\title{
ALGORITHMS OF POSITION AND VELOCITY ESTIMATION IN GPS RECEIVERS
}

\begin{abstract}
Processing of signals in Global Positioning System (GPS) receivers includes numerous signal and data operations leading to calculation of coordinates and velocities of satellites in global Earth-Centered Earth-Fixed (ECEF) frame of reference as well as pseudoranges and delta-ranges between the user and all the tracked GPS satellites. Further processing of these data consists in estimation of the user's position, velocity and time (PVT) and nowadays it is usually realized by means of an Extended Kalman Filters (EKF). The choice of measuring data processed by the Kalman filter significantly influences the accuracy of navigation solution. In simpler GPS receivers, the estimation of user's position and velocity is based on pseudoranges only, whereas in more advanced ones delta-ranges are also applied. The paper describes both possible solutions and compares the accuracy of estimation of the user's position and velocity in both cases. The comparison is based on simulation results, which are included in the paper.
\end{abstract}

\section{Keywords:}

GPS, positioning, Kalman filter, simulation.

\section{INTRODUCTION}

Basic observables formed in GPS receivers are pseudoranges, representing apparent transit times of signals between GPS satellites and the receiver, scaled in the units of distance [Januszewski, 2006], [Kaplan and Hegarty, 2006], [Narkiewicz, 2003], [Specht, 2007], [Spilker and Parkinson, 1996]. Most contemporary GPS receivers form also delta-ranges, based on Doppler-frequency-shift 
measurements [Kaplan and Hegarty, 2006], [Misra and Enge, 2012]. The delta-ranges are scaled in units of velocity and represent apparent relative velocities of the user with respect to the GPS satellites. The observables of pseudoranges and delta-ranges, along with the positions and velocities of GPS satellites, calculated on the basis of data extracted from GPS navigation messages, are used in receivers to solve for the user's position, velocity and time (PVT) [Kaplan and Hegarty, 2006], [Misra and Enge, 2012], [Spilker and Parkinson, 1996].

Some GPS receivers calculate also accumulated delta-ranges (ADR) [Spilker and Parkinson, 1996] which keep track of the distance changes between the user and the satellites. They are much more precise than code-based pseudoranges, but in contrast to them they have ambiguous starting value and cannot be used for standalone positioning. ADRs are usually used for smoothing pseudoranges, in differential GPS or for attitude determination. These methods and applications, however, are out of the scope of this paper and therefore ADR observables are not considered here.

Due to the lack of synchronism of a relatively low-quality GPS receiver clock with high-accuracy clocks installed in satellites, both pseudoranges and delta-ranges contain significant components connected with the clock errors. These components represent additional variables of bias and drift which have to be estimated along with the user's position and velocity. Fortunately, the receiver clock bias is common to all the observed pseudoranges and the clock drift is common to all the observed delta-ranges, and therefore their estimation is relatively simple.

The pseudoranges and delta-ranges from the user to the $i$-th GPS satellite are non-linearly related to the user's position and velocity by the following equations [Kaplan and Hegarty, 2006] Misra and Enge, 2012]:

$$
\begin{gathered}
\rho_{i}=\left|\mathbf{r}_{i}-\mathbf{r}_{u}\right|+b+\varepsilon_{\rho i} ; \\
\dot{\rho}_{i}=\left(\mathbf{v}_{i}-\mathbf{v}_{u}\right) \frac{\mathbf{r}_{i}-\mathbf{r}_{u}}{\left|\mathbf{r}_{i}-\mathbf{r}_{u}\right|}+d+\varepsilon_{\dot{\rho} i},
\end{gathered}
$$

where:

$\rho_{i} \quad$ - pseudorange between the user and the $i$-th satellite,

$\dot{\rho}_{i} \quad$ - delta-range between the user and the $i$-th satellite,

$\mathbf{r}_{i}=\left[\begin{array}{lll}X_{i} & Y_{i} & Z_{i}\end{array}\right]^{T}$ - position of the $i$-th satellite, 


$$
\begin{aligned}
& \mathbf{r}_{u}=\left[\begin{array}{lll}
x & y & z
\end{array}\right]^{T} \quad \text { - user's position, } \\
& \mathbf{v}_{i}=\left[\begin{array}{lll}
V_{x i} & V_{y i} & V_{z i}
\end{array}\right]^{T} \text { - velocity of the } i \text {-th satellite, } \\
& \mathbf{v}_{u}=\left[\begin{array}{lll}
v_{x} & v_{y} & v_{z}
\end{array}\right]^{T} \text { - user's velocity, } \\
& b \\
& d \\
& \varepsilon_{\rho i} \\
& \varepsilon_{\dot{\rho} i} \\
& \text { - bias in the GPS receiver clock scaled in distance units [m], } \\
& \text { - drift in the GPS receiver clock scaled in velocity units }[\mathrm{m} / \mathrm{s}] \text {, } \\
& \text { - pseudorange measurement error, } \\
& \text { - delta-range measurement error. }
\end{aligned}
$$

To calculate the position and velocity of the user, it is necessary to solve a set of the above equations, formulated for several visible and tracked GPS satellites. The GPS positioning is realised in Cartesian ECEF (WGS-84) coordinate frame of reference [Januszewski, 2006], [Specht, 2007]. There exist numerous concepts of PVT estimation, which can be divided into single-point solutions and kinematic solutions algorithms. Typical possible approaches to PVT calculations are discussed in the following chapter.

\section{SINGLE-POINT PVT ESTIMATION METHODS}

The simplest methods of PVT calculation are single-point solutions algorithms, processing only pseudoranges. They include ordinary-least-squares (OLS) and weighted-least-squares (WLS) methods which iteratively estimate the user's position and receiver clock bias [Kaplan and Hegarty, 2006], [Specht, 2007], [Spilker and Parkinson, 1996].

If we assume an a priori user's position $\hat{\mathbf{r}}_{u}$ and GPS receiver clock bias $\hat{b}$, as well as calculate a predictable part of the pseudorange measurement error $\hat{\varepsilon}_{\rho i}$, we can calculate predicted pseudoranges for all the tracked satellites as follows [Kaplan and Hegarty, 2006], [Misra and Enge, 2012]:

$$
\hat{\rho}_{i}=\left|\mathbf{r}_{i}-\hat{\mathbf{r}}_{u}\right|+\hat{b}+\hat{\varepsilon}_{\rho i} .
$$

By subtracting the equation (1) from (3) by sides we obtain the following equation:

$$
\hat{\rho}_{i}-\rho_{i}=\left|\mathbf{r}_{i}-\hat{\mathbf{r}}_{u}\right|-\left|\mathbf{r}_{i}-\mathbf{r}_{u}\right|+\hat{b}-b+\hat{\varepsilon}_{\rho i}-\varepsilon_{\rho i}
$$


which can be linearized by the Taylor expansion method into the following form [Misra and Enge, 2012]:

$$
\Delta \rho_{i} \approx\left[\begin{array}{ll}
-\hat{\mathbf{1}}_{i}^{T} & 1
\end{array}\right]\left[\begin{array}{l}
\Delta \mathbf{r} \\
\Delta b
\end{array}\right]+\Delta \varepsilon_{\rho i}
$$

where:

$$
\Delta \rho_{i}=\hat{\rho}_{i}-\rho_{i}, \quad \hat{\mathbf{1}}_{i}^{T}=\frac{\mathbf{r}_{i}-\hat{\mathbf{r}}_{u}}{\left|\mathbf{r}_{i}-\hat{\mathbf{r}}_{u}\right|}, \Delta \mathbf{r}=\hat{\mathbf{r}}_{u}-\mathbf{r}_{u}, \Delta b=\hat{b}-b, \Delta \varepsilon_{\rho i}=\hat{\varepsilon}_{\rho i}-\varepsilon_{\rho i} .
$$

A set of equations of the type (5) for all the tracked GPS satellites can be combined into a single formulae:

$$
\Delta \boldsymbol{\rho}=\left[\begin{array}{llll}
\Delta \rho_{1} & \Delta \rho_{2} & \ldots & \Delta \rho_{M}
\end{array}\right]^{T}=\mathbf{H}\left[\begin{array}{c}
\Delta \mathbf{r} \\
\Delta b
\end{array}\right]+\Delta \boldsymbol{\varepsilon}_{\boldsymbol{\rho}}=\mathbf{H} \Delta \mathbf{x}+\Delta \boldsymbol{\varepsilon}_{\boldsymbol{\rho}}
$$

where:

$M$ — the number of tracked GPS satellites and the number of pseudoranges.

A single-point OLS solution of the equation (7) for a full-rank geometry matrix $\mathbf{H}$ is generally calculated with the use of a so-called pseudo-inversion:

$$
\Delta \hat{\mathbf{x}}=\left(\mathbf{H}^{T} \mathbf{H}\right)^{-1} \mathbf{H}^{T} \Delta \boldsymbol{\rho} .
$$

A more advanced and allegedly more accurate single-point WLS method introduces additionally different weights to the measurements of pseudoranges, based on their unequal accuracy. Calculation of these weights can be realized in many ways, but typically it is implemented in the GPS receiver as a monotonic function (or look-up table) which values depend on satellite elevation angle and/or signal to noise ratio (SNR), as smaller elevations and weaker signals usually result in worse accuracy of pseudoranges [Misra and Enge, 2012].

If we assume that a diagonal measurement errors covariance matrix $\mathbf{R}$ is known and it contains along its diagonal variances of all the pseudoranges used in the navigation solution, we can weigh the observables by the $\mathbf{R}^{-1}$ weighting matrix:

$$
\Delta \hat{\mathbf{x}}=\left(\mathbf{H}^{T} \mathbf{R}^{-1} \mathbf{H}\right)^{-1} \mathbf{H}^{T} \mathbf{R}^{-1} \Delta \boldsymbol{\rho}
$$


The estimated vector $\Delta \hat{\mathbf{x}}=\left[\begin{array}{ll}\Delta \hat{\mathbf{r}} & \Delta \hat{b}\end{array}\right]^{T}$ obtained with the use of OLS or WLS is used for correction of the initially guessed user's position $\hat{\mathbf{r}}_{u}$ and clock bias $\hat{b}$ as follows:

$$
\hat{\mathbf{r}}_{u} \leftarrow \hat{\mathbf{r}}_{u}-\Delta \hat{\mathbf{r}}, \quad \hat{b} \leftarrow \hat{b}-\Delta \hat{b}
$$

If the initial estimates of the user's position and receiver clock were very far from their real values, the above steps, including recalculation of the geometry matrix $\mathbf{H}$, should be iteratively repeated, sometimes several times, until the norm of the correcting vector $|\Delta \hat{\mathbf{x}}|$ falls below an assumed threshold, e.g. $0.001 \mathrm{~m}$ [Specht, 2007].

Once the single-point user's position is known, the user's velocity can be calculated. In GPS receivers with implemented OLS or WLS algorithms and using only pseudoranges approximate derivatives of positions estimated in successive time epochs can be used for this purpose [Kaplan and Hegarty, 2006]:

$$
\hat{\mathbf{v}}_{u}\left(t_{k+1}\right)=\frac{\hat{\mathbf{r}}_{u}\left(t_{k+1}\right)-\hat{\mathbf{r}}_{u}\left(t_{k}\right)}{t_{k+1}-t_{k}} .
$$

The above method gives acceptable results only for almost constant velocity motions and otherwise introduces significant errors. Thus, if delta-ranges $\dot{\rho}_{i}$ are available in the GPS receiver, much better accuracy of the user's velocity $\mathbf{v}_{\mathbf{u}}$ can be achieved with the use of OLS or WLS methods [Kaplan and Hegarty, 2006], [Misra and Enge, 2012]. Similarly, as in the case of position estimation, it requires an assumption of an a priori user's velocity $\hat{\mathbf{v}}_{u}$, GPS receiver clock drift $\hat{\dot{b}}$ and calculation of a predictable part of the delta-range measurement error $\hat{\varepsilon}_{\dot{\rho} i}$. The following linearized relationship, similar to the equation (7) and with the same geometry matrix $\mathbf{H}$, holds [Misra and Enge, 2012]:

$$
\Delta \dot{\boldsymbol{\rho}}=\left[\begin{array}{llll}
\Delta \dot{\rho}_{1} & \Delta \dot{\rho}_{2} & \ldots & \Delta \dot{\rho}_{M}
\end{array}\right]^{T}=\mathbf{H}\left[\begin{array}{c}
\Delta \mathbf{v} \\
\Delta \dot{b}
\end{array}\right]+\Delta \boldsymbol{\varepsilon}_{\dot{\boldsymbol{\rho}}}
$$

where:

$$
\Delta \dot{\rho}_{i}=\hat{\dot{\rho}}_{i}-\dot{\rho}_{i}, \quad \Delta \mathbf{v}=\hat{\mathbf{v}}_{u}-\mathbf{v}_{u}, \quad \Delta \dot{b}=\hat{\dot{b}}-\dot{b}, \Delta \varepsilon_{\dot{\rho} i}=\hat{\varepsilon}_{\dot{\rho} i}-\varepsilon_{\dot{\rho} i} .
$$

The above equation can be solved iteratively by the OLS or WLS algorithm as follows: 
OLS:

$$
\left[\begin{array}{c}
\Delta \hat{\mathbf{v}} \\
\Delta \hat{\dot{b}}
\end{array}\right]=\left(\mathbf{H}^{T} \mathbf{H}\right)^{-1} \mathbf{H}^{T} \Delta \dot{\boldsymbol{\rho}} ;
$$

WLS:

$$
\left[\begin{array}{c}
\Delta \hat{\mathbf{v}} \\
\Delta \hat{\dot{b}}
\end{array}\right]=\left(\mathbf{H}^{T} \mathbf{R}^{-1} \mathbf{H}\right)^{-1} \mathbf{H}^{T} \mathbf{R}^{-1} \Delta \dot{\boldsymbol{\rho}},
$$

however, an errors covariance matrix $\mathbf{R}$ in this case contains on its diagonal the variances of all delta-ranges used in the navigation solution.

\section{KINEMATIC PVT ESTIMATION METHODS}

The described single-point methods do not use information from previous steps of data processing, as for any new portion of observables, a new PVT solution is calculated. Going a step further, it is possible to model the user's motion and use this model for prediction of position and velocity as well as clock errors at the next epoch, based on the navigation solution from the previous epoch. This way, information from historical measurements is preserved in new solutions and the estimated data are less prone to rapid changes of satellite geometry or accuracy of measurements. The new observables in this concept are used for correction of the previous solution, thus even if less than four GPS satellites are tracked, the new estimates can still be obtained. In such a case, the matrix $\mathbf{H}$ in OLS or WLS would become rank-deficient and no solution would be calculated.

There exist models of motion applicable to diverse types of users (platforms or vehicles). They can be divided into two groups, i.e. dynamics models and kinematics models. Properly formulated dynamics models are more accurate than the kinematics ones but they are expressed by a set of complicated non-linear differential equations and require good knowledge of the platform's size, weight, geometry and parameters of environment (e.g. air density, temperature etc.). Thus they are cumbersome in use, especially in GPS receivers, which can be fitted to any type of platform. The kinematics models are simpler and more universal and for this reason they are better suited for use in GPS receivers.

The kinematics models are based on first-order, linear differential equations, expressing relationships between the user's position, velocity, acceleration and so on. Such models are driven by Gaussian white noises, representing uncertainties in the model and connected with unknown steering forces (unknown actions of the driver/pilot/operator) as well as unknown influences of the environment, e.g. 
random gusts of wind etc. Typical models used for this purpose are models: P (like Position), PV (like Position/Velocity) and PVA (like Position/ Velocity/Acceleration). They contain different numbers of state variables and are suitable for platforms of different level of manoeuvrability.

For almost stationary or very slowly and randomly moving platforms, such as sea buoys, tethered balloons, etc., the best suited model is the P model, which assumes that the position changes are caused by random disturbances, physically caused by waves, wind gusts etc. Such a model is given as follows:

$$
\dot{\mathbf{r}}_{u}=\mathbf{u},
$$

where:

$\mathbf{r}_{u} \quad$ - the user's position,

u - represents random velocity, modelled as a vector of zero-mean Gaussian white noises.

For non-manoeuvring, regularly displacing platforms the PV model can be applied. It is often used for modelling the movement of pedestrians, land vehicles, ships or civilian aircraft, which is usually composed of relatively long-lasting segments of almost uniform and rectilinear motion. Disturbances of motion, i.e. changes of velocity $\mathbf{v}$ are modelled as random accelerations contained in the vector $\mathbf{u}$. Such a model is given as follows:

$$
\dot{\mathbf{r}}_{u}=\mathbf{v}, \dot{\mathbf{v}}=\mathbf{u} .
$$

The PVA model is best suitable for manoeuvring platforms, frequently changing velocity and direction, e.g. military aircraft, UAVs, etc. Their motion is characterised by presence of relatively long segments with significant values of acceleration a, which for this reason is included into the PVA model as follows:

$$
\dot{\mathbf{r}}_{u}=\mathbf{v}, \quad \dot{\mathbf{v}}=\mathbf{a}, \quad \dot{\mathbf{a}}=\mathbf{u} .
$$

It this model, the vector of disturbances $\mathbf{u}$ represents random changes of jerk (derivative of acceleration).

The most popular estimation algorithm used in contemporary GPS receivers, realizing a kinematic PVT solution, is the Extended Kalman Filter (EKF) [Brown and Hwang, 2012], [Felski and Jakubowski, 2004], [Grewal et al., 2007], Mao et al., 2012], [Yamaguchi and Tanaka, 2006]. It is a modified version of the standard Kalman Filter, which can deal with a non-linearity of the following relationships between the observables and variables of interest (position and velocity): 


$$
\begin{aligned}
& \rho_{i}=\left|\mathbf{r}_{i}-\mathbf{r}_{u}\right|+b+\varepsilon_{\rho i}=\sqrt{\left(X_{i}-x\right)^{2}+\left(Y_{i}-y\right)^{2}+\left(Z_{i}-z\right)^{2}}+b+\varepsilon_{\rho i} ; \\
& \dot{\rho}_{i}=\left(\mathbf{v}_{i}-\mathbf{v}_{u}\right) \frac{\mathbf{r}_{i}-\mathbf{r}_{u}}{\left|\mathbf{r}_{i}-\mathbf{r}_{u}\right|}+d+\varepsilon_{\dot{\rho} i}= \\
& =\frac{\left(x-X_{i}\right)\left(v_{x}-V_{x i}\right)+\left(y-Y_{i}\right)\left(v_{y}-V_{y i}\right)+\left(z-Z_{i}\right)\left(v_{z}-V_{z i}\right)}{\sqrt{\left(X_{i}-x\right)^{2}+\left(Y_{i}-y\right)^{2}+\left(Z_{i}-z\right)^{2}}}+d+\varepsilon_{\dot{\rho} i}
\end{aligned}
$$

The EKF algorithm is composed of several steps shown in the Figure 1 as steps from (1) to (5). The presented version of EKF is a modified (simplified) algorithm, applicable in systems with a linear model of dynamics and a non-linear observation model [Kaniewski, 2010]. Such a simplification is justified, because the implementation of the Kalman filter presented in this paper is based on the previously described linear PVA model of motion and non-linear observation model given by the equations (19) and (20).

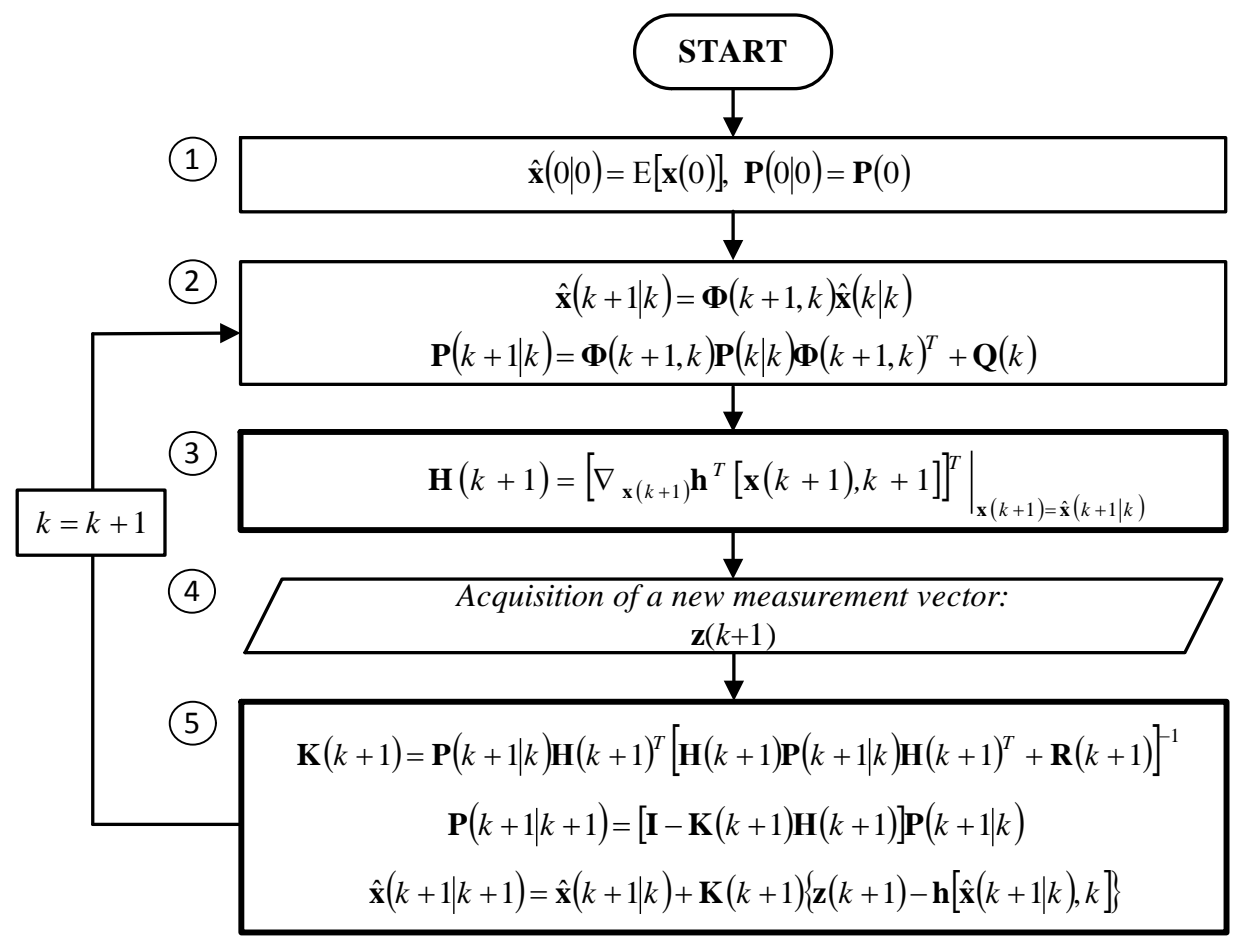

Fig. 1. Extended Kalman Filter for linear model of dynamics and non-linear observation model 
The presented algorithm includes its initialization (1), prediction (2), linearization of the observation model, which consists in calculation of the observation matrix $\mathbf{H}$ (3), acquisition of a new measurement vector (4) and its use for correction of the results of prediction. The symbols used in the above scheme are as follows: $\mathbf{x}(0)$ - initial state vector, $\mathbf{P}(0)$ — initial covariance matrix, $\hat{\mathbf{x}}(k \mid k)$ - state vector estimated at time step $k, \hat{\mathbf{x}}(k+1 \mid k)$ - predicted state vector at time step $k+1, \hat{\mathbf{x}}(k+1 \mid k+1)$ — corrected state vector at time step $k+1, \mathbf{P}(k \mid k)$ covariance matrix of filtration errors at time step $k, \mathbf{P}(k+1 \mid k)$ - covariance matrix of prediction errors at time step $k+1, \mathbf{P}(k+1 \mid k+1)$ - covariance matrix of filtration errors at time step $k+1, \mathbf{K}(k+1)$ - Kalman gains matrix at time step $k+1, \mathbf{h}()$ - observation function, $\mathbf{\Phi}$ - transition matrix, $\mathbf{Q}$ - covariance matrix of discrete process disturbances, $\mathbf{H}$ - observation matrix, $\mathbf{R}$ - covariance matrix of measurement errors.

The matrices $\Phi$ and $\mathbf{Q}$ are constant and can be considered as parameters of a discrete version of the model of dynamics [Brown and Hwang, 2012], [Kaniewski, 2010]. They have been calculated under an assumption that the kinematic PVA model properly describes the user's motion. Thus the state vector $\mathbf{x}$ contains 9 states for navigation elements (3 states for position, 3 for velocity and 3 for acceleration) augmented with 2 states for the GPS receiver clock errors (bias and drift):

$$
\mathbf{x}=\left[\begin{array}{lllllllllll}
x & w_{x} & a_{x} & y & w_{y} & a_{y} & z & w_{z} & a_{z} & b & d
\end{array}\right]^{\mathrm{T}} .
$$

The $\Phi$ matrix describes how the above states change from step $k$ to $k+1$ and the $\mathbf{Q}$ matrix represents the intensity of equivalent discrete disturbances of the model [Grewal et al, 2007]. The methods of discretization (sampling) of the originally continuous dynamics model can be found e.g. at [Kaniewski, 2010]. The covariance matrix of measurement errors $\mathbf{R}$ has also been assumed to be constant. Depending on the version of the filter it contains along its diagonal variances of pseudoranges or pseudoranges and delta-ranges. 


\section{SIMULATON RESULTS}

The designed EKF filters for a GPS receiver have been tested in MATLAB ${ }^{\circledR}$ software environment. Firstly, a user's trajectory, typical for highly maneuvering aircraft has been generated. For the assumed trajectory, trajectories of visible GPS satellites have been generated and ideal relative distances and velocities between the user and satellites have been calculated. Subsequently, GPS receiver clock errors and measurement errors of pseudoranges and delta-ranges have been generated. For simplicity, errors of GPS observables have been assumed uncorrelated Gaussian random sequences with standard deviation $\sigma_{\rho}=1 \mathrm{~m}$ for pseudoranges and $\sigma_{\dot{\rho}}=0.02 \mathrm{~m} / \mathrm{s}$ for delta-ranges.

The simulations have been run for the same trajectory of aircraft with use of two designed EKF filters. The first filter uses only GPS pseudoranges, whereas the second one processes also delta-ranges. Errors of estimation of the user's position and velocity in the East, North and Down directions with the use of both filters are compared in Figures 2, 3.

As can be seen from the above figures, both position and velocity errors are significantly smaller when delta-ranges are processed along with the pseudoranges in the Kalman filter. In order to quantitatively assess the accuracies of various algorithms, the root mean-squared (RMS) errors of positioning for the whole period of simulation with use of both EKF filters and a single-point solution (OLS) method are compared in Table 1.

Tab. 1. Errors of positioning in GPS receiver with OLS and EKF filters

\begin{tabular}{|c|c|c|c|}
\hline Type of algorithm & $\begin{array}{c}\mathbf{R M S}(\boldsymbol{\delta} \mathbf{N}) \\
{[\mathrm{m}]}\end{array}$ & $\begin{array}{c}\mathbf{R M S}(\boldsymbol{\delta E}) \\
{[\mathrm{m}]}\end{array}$ & $\begin{array}{c}\mathbf{R M S}(\boldsymbol{\delta D}) \\
{[\mathrm{m}]}\end{array}$ \\
\hline OLS & 0.788 & 0.625 & 1.59 \\
\hline EKF with pseudoranges & 0.684 & 0.555 & 1.06 \\
\hline $\begin{array}{l}\text { EKF with pseudoranges } \\
\text { and delta-ranges }\end{array}$ & 0.336 & 0.279 & 0.568 \\
\hline
\end{tabular}



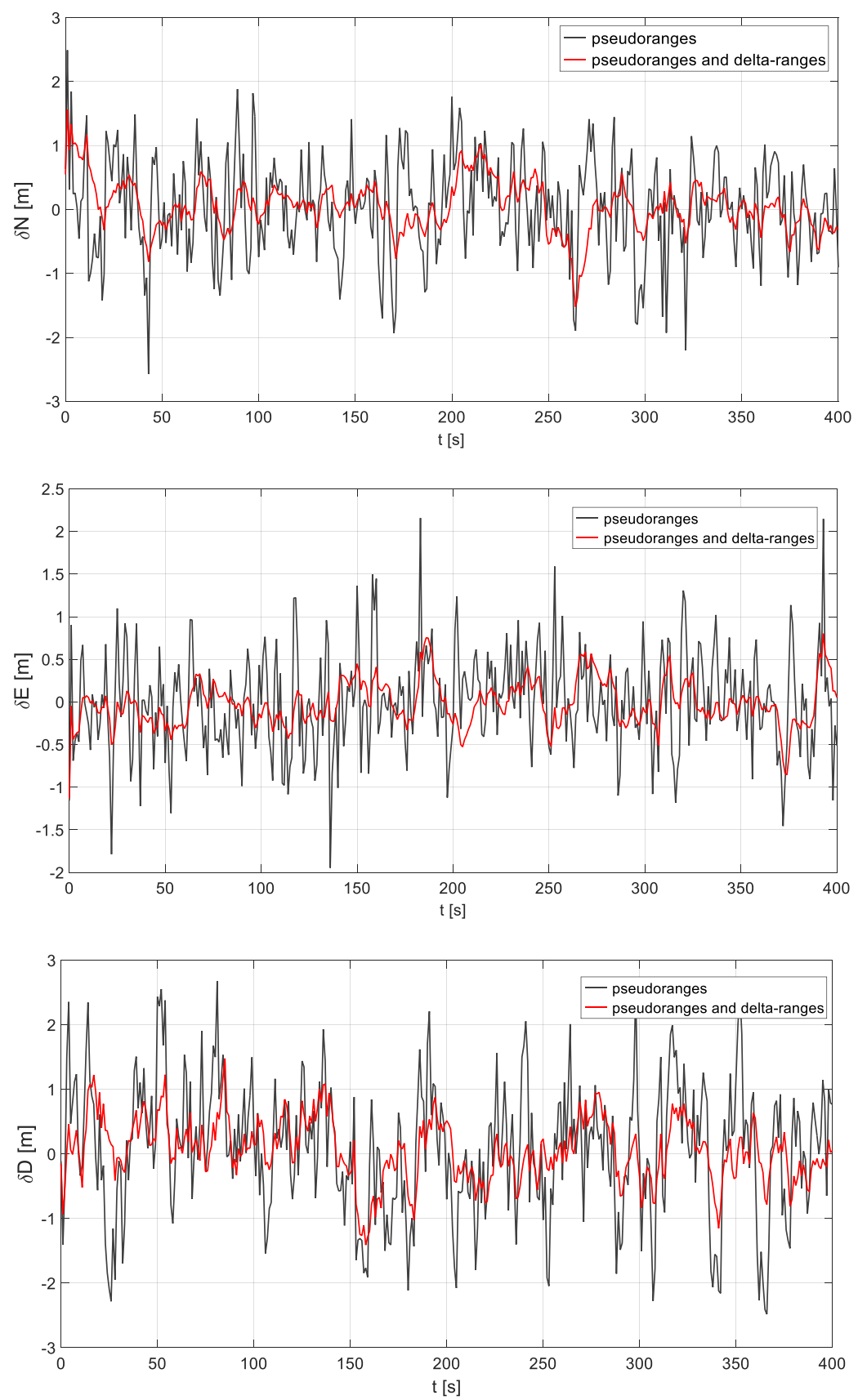

Fig. 2. Errors of estimation of the user's position 

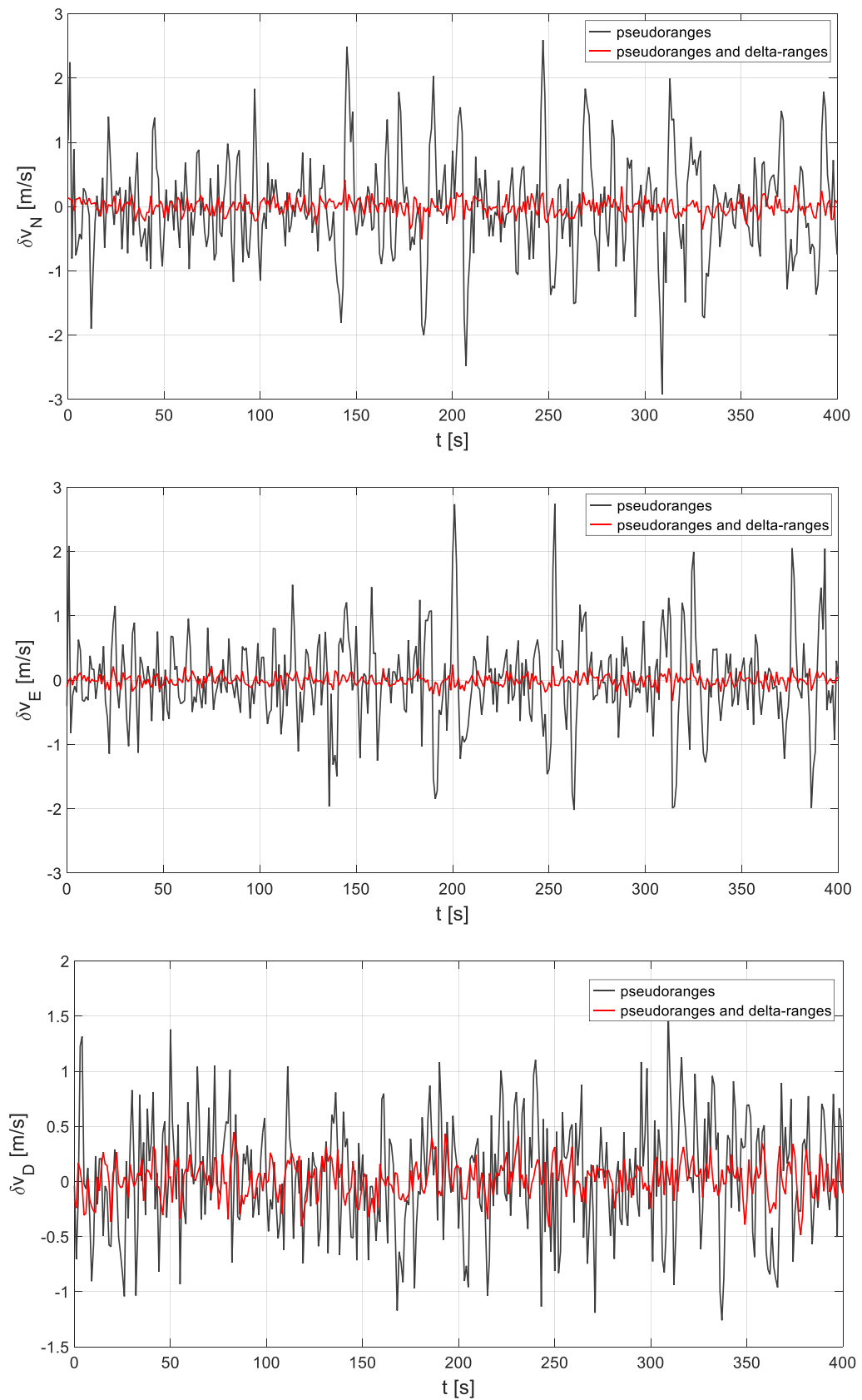

Fig. 3. Errors of estimation of the user's velocity 
The ability of both EKF filters to estimate the GPS receiver clock bias and drift are demonstrated in Figures 4, 5. As can be seen the estimates of bias and drift closely follow their real (simulated) values. The differences between these estimates and the real (simulated) values of bias and drift for both filters are presented in Figures 6, 7. Similarly to the estimates of the user's position and velocity, the estimates of clock errors are also more accurate when delta-ranges are used by the Kalman filter.

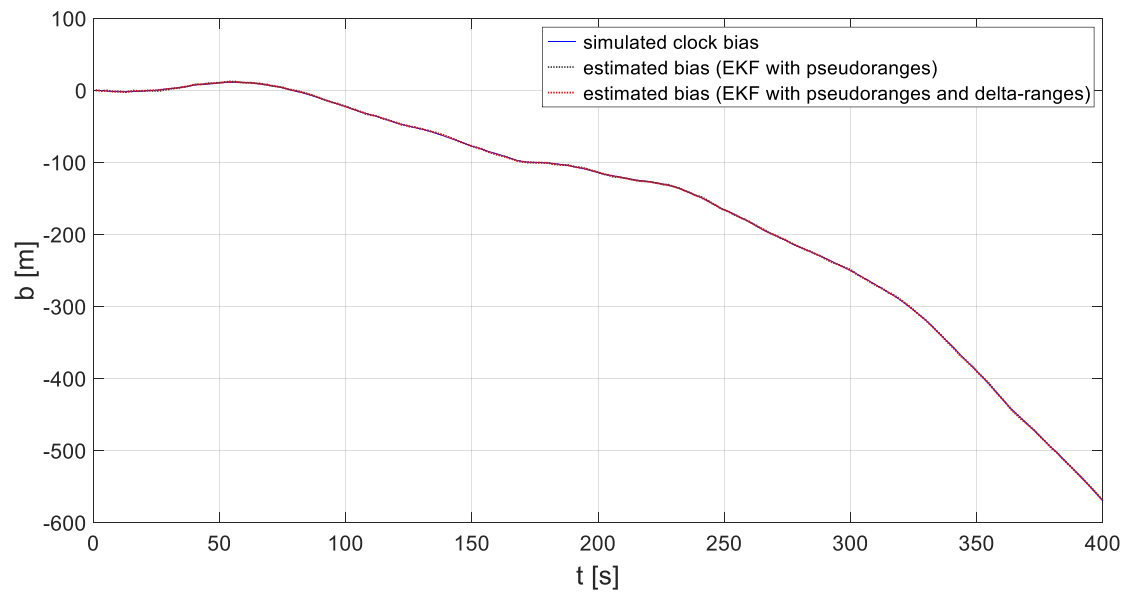

Fig. 4. Results of GPS receiver clock bias estimation

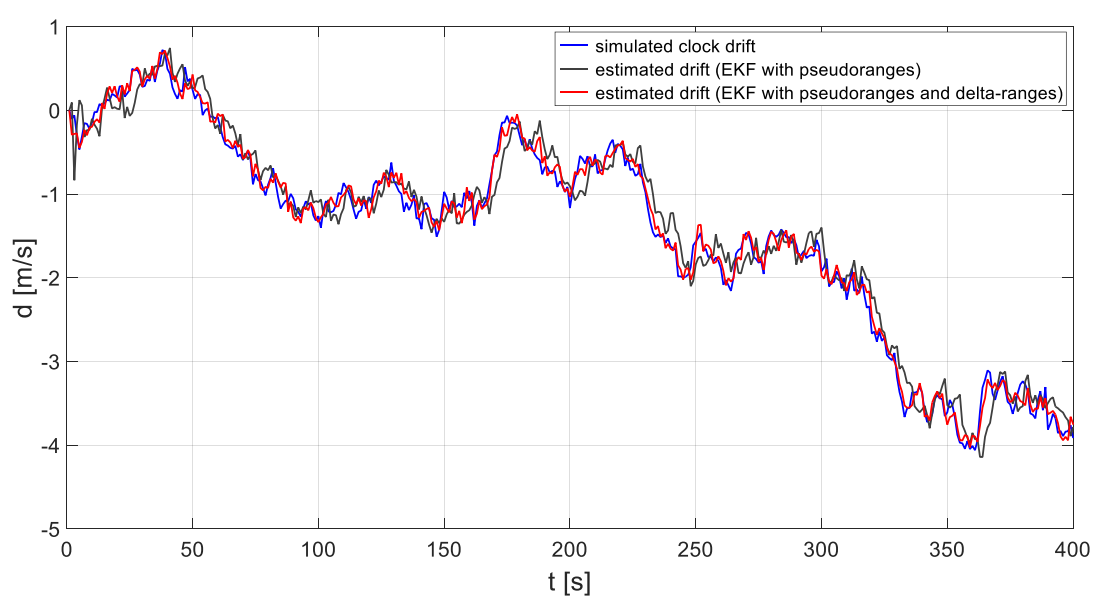

Fig. 5. Results of GPS receiver clock drift estimation 


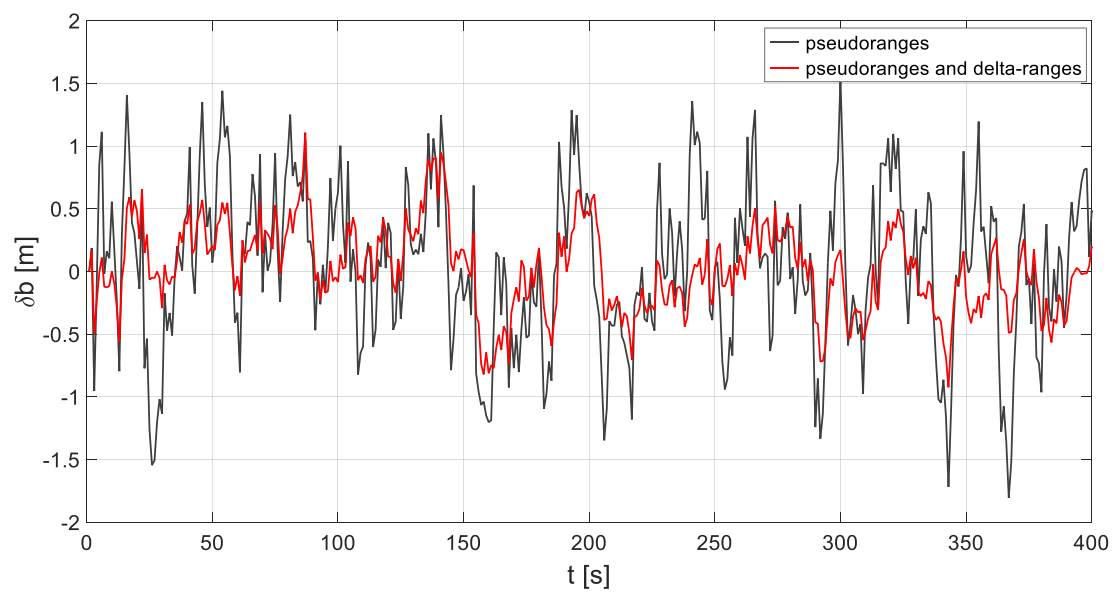

Fig. 6. Errors of GPS receiver clock bias estimation

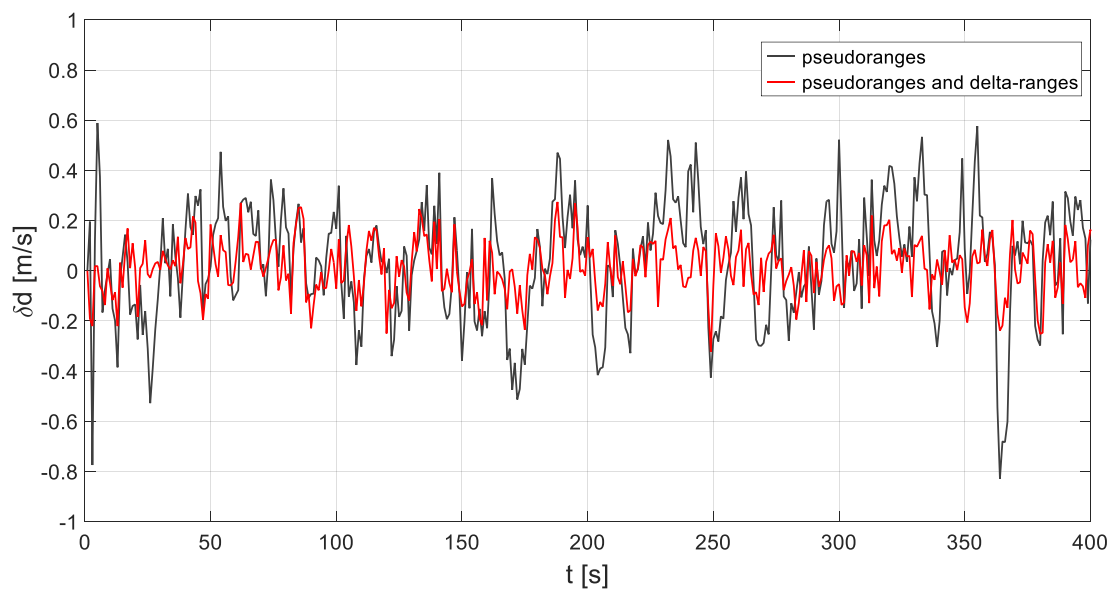

Fig. 7. Errors of GPS receiver clock drift estimation

\section{CONCLUSIONS}

On the basis of the simulation results presented in the paper we can conclude that the use of an EKF filter with properly chosen dynamics model in the GPS receiver ensures its better accuracy than the use of simple OLS algorithm. Moreover the Kalman filter is more flexible than OLS or WLS and can provide valuable data also in case of incomplete measurement situation, e.g. when less than four GPS satellites are visible. 
The choice of measuring data processed by the Kalman filter significantly influences the accuracy of navigation solution. The EKF processing the delta-ranges along with the pseudoranges is much more accurate than the simpler Kalman filter processing only pseudoranges. Thus, whenever possible the EKF processing both types of observables should be a preferable solution for the GPS user's positioning.

\section{REFERENCES}

[1] Brown R. G., Hwang P. Y. C., Introduction to random signals and applied Kalman filtering, Wiley, UK, 2012.

[2] Felski A., Jakubowski B., Reliability of navigation system in the frame of navigation information processing [in Polish], 'Zeszyty Naukowe Akademii Marynarki Wojennej', 2004, No. 1, pp. 5-22.

[3] Grewal M. S., Weill L. R., Andrews A. P., Global Positioning Systems, Inertial Navigation and Integration, 2nd Edition, John Wiley \& Sons, USA, 2007.

[4] Januszewski J., Satellite systems GPS, Galileo and others [in Polish], PWN, Warszawa 2006.

[5] Kaniewski P., Structures, models and algorithms in integrated positioning and navigation systems [in Polish], WAT, Warszawa 2010.

[6] Kaplan E. D., Hegarty C. J. (eds.), Understanding GPS — Principles and Applications, Artech House, USA, 2006.

[7] Mao X., Wada M., Hashimoto H., Investigation on Nonlinear Filtering Algorithms for GPS, IEEE Intelligent Vehicle Symposium, 17-21 June 2002, Vol. 1, pp. 64-70.

[8] Misra P., Engle P., Global Positioning System - Signals, Measurements, and Performance, Ganga-Jamuna Press, USA, 2012.

[9] Narkiewicz J., Global positioning system [in Polish], WKŁ, Warszawa 2003.

[10] Reina G., Vargas A., Nagatani K., Yoshida K., Adaptive Kalman Filtering for GPS-based Mobile Robot Localization, IEEE International Workshop on Safety, Security and Rescue Robotics, Rome 2007, pp. 1-6.

[11] Specht C., GPS system[in Polish], Publ. Bernardinum, Pelplin 2007.

[12] Spilker J., Parkinson B. (eds.), Global Positioning System: Theory and Applications, Vol. I, American Institute of Aeronautics and Astronautics, USA, 1996.

[13] Yamaguchi S., Tanaka T., GPS Standard Positioning using Kalman filter, SICE-ICASE International Joint Conference, Busan 2006, pp. 1351-1354.

Received August 2016

Reviewed November 2016 


\section{PIOTR KANIEWSKI}

Military University of Technology

Kaliskiego 2 Str., 201-476 Warsaw, Poland

e-mail: piotr.kaniewski@wat.edu.pl

\section{RAFAL GIL}

Military University of Technology

Kaliskiego 2 Str., 201-476 Warsaw, Poland

e-mail: rafal.gil@wat.edu.pl

\section{STANISŁAW KONATOWSKI}

Military University of Technology

Kaliskiego 2 Str., 201-476 Warsaw, Poland

e-mail: stanislaw.konatowski@wat.edu.pl

\section{STRESZCZENIE}

Przetwarzanie sygnałów odbieranych w odbiorniku GPS obejmuje szereg operacji, w wyniku których wyznaczane są między innymi współrzędne i prędkości satelitów w globalnym układzie współrzędnych ECEF oraz pseudoodległości i zmiany pseudoodległości pomiędzy użytkownikiem systemu a poszczególnymi obserwowanymi satelitami. Dalsze przetwarzanie uzyskanych danych polega zwykle na estymacji położenia i prędkości użytkownika za pomocą algorytmu rozszerzonego filtru Kalmana (EKF). Wybór danych pomiarowych przetwarzanych przez filtr istotnie wpływa na dokładność rozwiązania nawigacyjnego. W prostszych odbiornikach do estymacji położenia i prędkości użytkownika wykorzystywane są wyłącznie pseudoodległości, natomiast w rozwiązaniach bardziej zaawansowanych również zmiany pseudoodległości. W artykule szczegółowo omówiono oba rozwiązania oraz porównano dokładności estymacji położenia i prędkości użytkownika w obu przypadkach. Rozważania poparto zamieszczonymi w artykule wynikami badań symulacyjnych. 